\title{
Editorial \\ Rheumatoid cachexia: a complication of rheumatoid arthritis moves into the 21st century
}

\author{
Ronenn Roubenoff ${ }^{1,2}$
}

1 Immunology R\&D, Biogen Idec, Inc., Cambridge, MA 02142, USA

2Tufts University and Tufts Medical Center, Boston, MA 02111, USA

Corresponding author: Ronenn Roubenoff, Ronenn.roubenoff@biogenidec.com

Published: 27 April 2009

This article is online at http://arthritis-research.com/content/11/2/108

Arthritis Research \& Therapy 2009, 11:108 (doi:10.1186/ar2658)

(c) 2009 BioMed Central Ltd

See related research article by Elkan et al., http://arthritis-research.com/content/11/2/R37

\begin{abstract}
Rheumatoid cachexia, loss of muscle mass and strength and concomitant increase in fat mass, is very common in patients with rheumatoid arthritis (RA). Despite great advances in the treatment of RA, it appears that rheumatoid cachexia persists even after joint inflammation improves. Rheumatoid cachexia may be an important risk factor for cardiovascular disease and excess mortality in RA. In this issue of Arthritis Research \& Therapy, Elkan and colleagues demonstrate a link between rheumatoid cachexia and metabolic syndrome, further reinforcing the need for therapy directed beyond inflammation and at the metabolic consequences of RA.
\end{abstract}

This issue of Arthritis Research \& Therapy includes an important article on rheumatoid cachexia by Elkan and colleagues [1] demonstrating that cachexia remains common in rheumatoid arthritis (RA) and is associated with a higher prevalence of metabolic syndrome and hypertension, which may contribute to the excess mortality of RA. Weight loss and muscle wasting are common features of untreated RA, as originally described by James Paget in the 19th century [2]. However, rheumatoid cachexia, from the Greek meaning 'bad condition', was not recognized as a common problem among patients with RA until relatively recently [3]. Rheumatoid cachexia refers to the loss of fat-free mass, predominantly skeletal muscle, that occurs in RA. Loss of body weight does not always occur; in fact, loss of body fat-free mass is often accompanied by increased fat mass and stable body weight. Rheumatoid cachexia may affect up to two-thirds of all patients with RA $[3,4]$. Elkan and colleagues, using a more conservative definition of both low fat-free mass and high fat mass, found that about a quarter of their patients were cachectic.

Evidence from cancer, heart failure, and HIV infection strongly points to weight loss as an independent predictor of poor outcome (reviewed in [5]). The average loss of fat-free mass among patients with RA is between $13 \%$ and $15 \%$ approximately one-third of the maximum survivable loss of fatfree mass [6]. Loss of fat-free mass and higher fat mass are each associated with greater disability in RA [7], and low body weight (that is, both fat and fat-free tissue) in patients with RA is associated with threefold higher mortality [8]. Thus, rheumatoid cachexia may be an important contributor to increased morbidity and premature mortality in RA.

A number of factors are likely involved in the pathogenesis of rheumatoid cachexia, including 'sarcoactive' cytokines, energy expenditure, protein metabolism, physical activity levels, and hormones. For example, the inflammatory cytokines tumor necrosis factor (TNF)- $\alpha$ and IL-1 $\beta$ are centrally involved in the pathogenesis of RA, but, in addition, these cytokines exert a powerful influence on whole-body protein and energy metabolism. Other sarcoactive molecules include IL-6, IFN- $\gamma$, transforming growth factor- $\beta 1$, and MyoD [9]. Patients with RA have higher rates of whole-body protein breakdown compared with young and elderly healthy subjects, and, furthermore, protein breakdown is directly associated with TNF- $\alpha$ production by peripheral blood mononuclear cells [10]. More recent research has suggested that skeletal muscle protein loss is dependent upon the signaling activities of both TNF- $\alpha$ and IFN- $\gamma$, and that nuclear factor kappa B activity is needed for these cytokines to induce muscle damage [11]. Nevertheless, although anti-TNF therapy improves insulin resistance in RA, it does not seem to reverse rheumatoid cachexia [12].

Patients with RA also have reduced physical activity as a result of joint pain and stiffness, metabolic changes leading to loss of muscle mass and strength, and simple disuse, perhaps related to general cautiousness with regard to physical activity. While the role of the growth hormone $(\mathrm{GH})$ -

$\mathrm{GH}=$ growth hormone; IFN = interferon; IL = interleukin; RA = rheumatoid arthritis; TNF = tumor necrosis factor. 
insulin-like growth factor 1 axis in altering muscle mass and strength during healthy aging is not fully understood, $\mathrm{GH}$ is known to decline with aging, and has been suggested to play a role in the pathogenesis of sarcopenia (age-related muscle loss) [13]. However, persistent $\mathrm{GH}$ deficiency does not appear to be the cause of rheumatoid cachexia [13]. Like $\mathrm{GH}$, insulin is a potent anabolic hormone, and insulin resistance has been shown to occur in inflammatory arthritis [14]. It is possible that the metabolic milieu created by a state of insulin resistance may permit cytokine-driven muscle loss, although this remains speculative.

Elkan and colleagues [1] also made two other important contributions to our understanding of rheumatoid cachexia. First, by demonstrating that dietary fat intake was not an independent risk factor for this complication, they added support to the notion that cachexia cannot be cured by dietary intervention alone. Second, the demonstration of increased metabolic syndrome in patients with rheumatoid cachexia underlines the complex interplay between fat mass, lean mass, and insulin resistance in RA. In addition, Elkan and colleagues' finding of lower levels of potentially protective antibodies against cardiovascular disease offers an intriguing hypothesis as to the mechanism of accelerated atherosclerosis in RA. As rheumatologists, we all properly focus on the joints and their protection in RA, but we should step back and evaluate the muscle and fat mass as well, and seek to protect our patients from the metabolic complications of RA in addition to its rheumatic sequelae.

\section{Competing interests}

$\mathrm{RR}$ is an employee of Biogen Idec, Inc. a biotechnology company that manufactures rituximab, which is approved for treatment of lymphoma and rheumatoid arthritis

\section{References}

1. Elkan A-C, Hakansson N, Frostegard J, Cederholm T, Hafstrom I: Rheumatoid cachexia is associated with dyslipidemia and low levels of atheroprotective natural antibodies against phosphorylcholine but not with dietary fat in patients with rheumatoid arthritis: a cross sectional study. Arthritis Res Therapy 2009, 11:R37.

2. Paget J: Nervous mimicry of organic diseases. Lancet 1873, 2: 727-729.

3. Roubenoff R, Roubenoff R, Ward L, Holland S, Hellmann D: Rheumatoid cachexia: depletion of lean body mass in rheumatoid arthritis. Possible association with tumor necrosis factor. J Rheumatol 1992, 19:1505-1510.

4. Engvall I-L, Elkan A-C, Tengstrand B, Cederholm T, Brismar K, Hafstrom I: Cachexia in rheumatoid arthritis is associated with inflammatory activity, physical disability, and low bioavailable insulin-like growth factor. Scand J Rheumatol 2008, 37:321328.

5. Roubenoff R, Kehayias J: The meaning and measurement of lean body mass. Nutr Rev 1991, 46:163-175.

6. Roubenoff R, Roubenoff RA, Cannon JG, Kehayias JJ, Zhuang $\mathrm{H}$ Dawson-Hughes B, Dinarello CA, Rosenberg IH: Rheumatoid cachexia: cytokine-driven hypermetabolism accompanying reduced body cell mass in chronic inflammation. J Clin Invest 1994, 93:2379-2386.

7. Giles J, Bartlett S, Anderson R, Fontaine K, Bathon J: Association of body composition with disability in rheumatoid arthritis: impact of appendicular fat and lean tissue mass. Arthritis Care Res 2008, 59:1407-1415.
8. Kremers H, Nicola P, Crowson C, Ballman K, Gabriel S: Prognostic importance of low body mass index in relation to cardiovascular mortality in rheumatoid arthritis. Arthritis Rheum 2004, 50:3450-3457

9. Zoico $E$, Roubenoff $R$ : The role of cytokines in regulating protein metabolism and muscle function. Nutr Rev 2002, 60: 39-51.

10. Rall LC, Rosen CJ, Dolnikowski G, Hartman WJ, Lundgren N, Abad LW, Dinarello CA, Roubenoff R: Protein metabolism in rheumatoid arthritis and aging: Effects of muscle strength training and tumor necrosis factor-alpha. Arthritis Rheum 1996, 39:1115-1124.

11. Guttridge D, Mayo M, Madrid L, Wang C-Y, Baldwin A: NFkappaB-induced loss of MyoD messenger RNA: possible role in muscle decay and cachexia. Science 2000, 289:2363-2366.

12. Metsios GS, Stavropoulos-Kalinoglou A, Douglas KM, Koutedakis Y, Nevill AM, Panoulas VF, Kita M, Kitas GD: Blockade of tumor necrosis factor-alpha in rheumatoid arthritis: effects on components of rheumatoid cachexia. Rheumatology 2007, 46: 1824-1827.

13. Rall LC, Walsmith JM, Snydman L, Reichlin S, Veldhuis JD, Kehayias JJ, Abad LW, Lundgren NT, Roubenoff R: Cachexia of rheumatoid arthritis is not explained by decreased growth hormone. Arthritis Rheum 2002, 46:2574-2577.

14. Chung CP, Oeser A, Solus JF, Gebretsadik T, Shintani A, Avalos I, Sokka T, Raggi P, Pincus T, Stein CM: Inflammation-associated insulin resistance. Arthritis Rheum 2008, 58:2105-2112. 